J. Clin. Chem. Clin. Biochem.

Vol. 27, 1989, pp. 163-167

(C) 1989 Walter de Gruyter \& Co. Berlin - New York

\title{
Radioimmunoassay for Immunoreactive Non-Collagenous Domain of Type IV Collagen (NC1) in Serum: Normal Pregnancy and Preeclampsia
}

\author{
By Ch. Bieglmayer
}

2nd Dept. of Obstetrics and Gynecology, University of Vienna and

\section{G. Hofer}

Pharmacognostic Institute, University of Vienna

(Received February 19/October 10, 1988)

The study is dedicated to the memory of Dr. H. Strecker, Radiochemical Laboratory of Hoechst AG, Frankfurt, FRG

Summary: The use of a magnetic separation agent in a modified radioimmunoassay for the non-collagenous cross-linked region (NC1) of basement membrane collagen is described. The rabbit anti-NC1 serum employed in the assay revealed a binding behaviour similar to that reported recently (Mark et al. (1985) Eur. J. Biochem. 146, 555-562; Schuppan et al. (1986) J. Clin. Invest. 78, 241-248) with respect to the integrity of NC1disulphide bridges, affinity to NC1 subunits and lack of reactivity with other determinants of type IV collagen. Immunoreactive serum NC1, which increased towards the end of gestation, showed a broad peak during the second trimester of pregnancy. In preeclampsia, immunoreactive serum-NC1 was slightly elevated.

\section{Introduction}

A non-collagenous cross-linked region (NC1) located at the C-terminal end of type IV collagen molecules was isolated by collagenase digestion $(3,4)$. This hexameric globular structure $\left(M_{\mathrm{r}}\right.$ about 170000$)$ was dissociated by denaturation into several subunits consisting of monomers with $M_{\mathrm{r}}$ of approximately 24000-28000 and dimers (Da, Db; $M_{\mathrm{r}}$ about $50000-56000$ ), which are derived either from single alpha (IV) chains or from cross-linked chains. NC1 is rich in hydrophobic amino acids and cysteine residues which form intrachain and intermolecular disulphide bridges $(5-7)$. An antigenic potential of NC1 is evident from animal models $(1,7)$. In addition, autoantibodies involved in Goodpasture's syndrome are reactive with monomer and dimer proteins isolated by collagenase digestion of glomerular basement membranes. These antigens apparently resemble NC1 subunits in size and amino acid content $(8,9)$. Recent investigations showed that a very cationic monomer, related to NC1 subunits but distinct in amino acid composition from alpha 1 (IV) and alpha 2 (IV) chains, seems to be the probable target in Goodpasture's syndrome $(10-12)$.

Radioimmunoassays for NC1 proved to be useful for studying type IV collagen synthesis in rats $(13,14)$ and basement membrane turnover in men (2). A distinct species specifity but only a small tissue specifity of a polyclonal antiserum to human placental NC1 was observed in radioimmuno-inhibition assays (1). Reduced NC1 was only a weak inhibitor.

In this report we describe a modified NC1 radioimmunoassay procedure using a magnetic immunoprecipitation agent. To characterize the $\mathrm{NC1}$ antiserum used in our experiments, we tested for the existence 
of reaction patterns similar to those of antisera recently described $(1,2)$. Furthermore, the concentration of immunoreactive serum NC1 was determined during pregnancy. We were prompted to report this data, since NC1 measurements from women with preeclamptic symptoms further support the hypothesis that this disease is connected to an impairment of basement membranes.

\section{Materials and Methods}

NC1 Radioimmunoassay

Purified NC1, radiolabeled NC1 and the rabbit anti-placentalNC1 serum (IV/8 K2BE, 1984) were generous gifts from the Radiochemical Laboratory of Hoechst AG, Frankfurt, FRG (NC1 was isolated from human placenta (4) and was iodinated with ${ }^{125}$ I Bolton Hunter reagent (15) yielding a specific radioactivity of approximately $370 \mathrm{MBq} / \mathrm{mg}$ ).

Several anti-rabbit antibodies were tested for their practicability in the separation step of the radioimmunoassay. Finally, a magnetic immunoprecipitation agent (code \# 22263, Serono, Freiburg, FRG) was selected because of low non-specific binding and a convenient separation procedure.

Components were dissolved in $140 \mathrm{mmol} / 1 \mathrm{NaCl}, 2 \mathrm{mmol} / \mathrm{KCl}$, $0.42 \mathrm{mmol} / \mathrm{l}$ Tween 20 and $7.5 \mathrm{mmol} / 1$ Soerensen buffer $\mathrm{pH} 7.3$. Using purified $\mathrm{NC} 1$ as standard, concentrations ranged from $42 \mu \mathrm{g} / 1$ to $1.31 \mu \mathrm{g} / \mathrm{l}$ by geometric dilution. Concentration of the radiolabeled NC1 was $10 \mu \mathrm{g} / \mathrm{l}$ and the titre of the rabbit anti$\mathrm{NC1}$ serum was 1:20000. All incubations were carried out in a cold room. Standards or samples $(100 \mu l)$ were pipetted at least in duplicate, then incubated with $50 \mu \mathrm{l}$ of $\mathrm{NC1}$ antiserum for 18 hours. Radiolabeled NC1 $(50 \mu \mathrm{l})$ was coincubated for an additional 7 hours, followed by addition of $200 \mu \mathrm{l}$ of a suspension of the separation agent in assay buffer. Settling of particles was avoided by shaking the tubes during incubation for one hour. Pellets obtained by magnetic separation were washed once with $800 \mu l$ buffer. Radioactivity was counted with a Packard Multiprias Gamma Scintillation Counter and the data were evaluated by a weighted 4 parameter logistic model.

\section{Characterisation of the rabbit anti-NC1 serum}

Purified placental NC1 (Hoechst) was modified by partial reduction and carboxymethylation (16). NC1 and reduced NC1 were analysed by sodium dodecylsulphate electrophoresis in $12 \%$ polyacryamide gels without 2 -mercaptoethanol in the sample buffer (17). Proteins were either silver-stained (18) or were blotted to a nitrocellulose membrane (Bio-Rad, USA) at $16 \mathrm{~V}$ for 20 hours using a Bio-Rad Transblot-cell filled with 30 $\mathrm{mmol} / \mathrm{l}$ borate buffer $\mathrm{pH} 8.9$. The membrane was blocked with $30 \mathrm{~g} / 1$ bovine serum albumin for 3 hours and was further incubated overnight with rabbit anti-NC1 serum (1:2000 diluted with radioimmunoassay buffer containing $10 \mathrm{~g} / \mathrm{l}$ albumin). After intensive washing with buffered physiological saline, the membrane was incubated with ${ }^{125}$ I-labelled anti-rabbit IgG (about 200000 counts/min $\cdot \mathrm{ml}$ in radioimmunoassay buffer; Amersham, UK) for one hour. Autoradiography of the washed and dried membrane was performed with a Hyperfilm-MP (Amersham). Specifity of the reaction was demonstrated by omitting the anti-NC1 serum, which resulted in a loss of darkening on the film.

Human glomerular basement membranes served as a source for the isolation of NC1 according to a procedure described by Wieslander \& Heinegard for crude Goodpasture antigen (19). Briefly, glomerular basement membranes were prepared (8), then digested with collagenase (CLSPA, Worthington, UK).

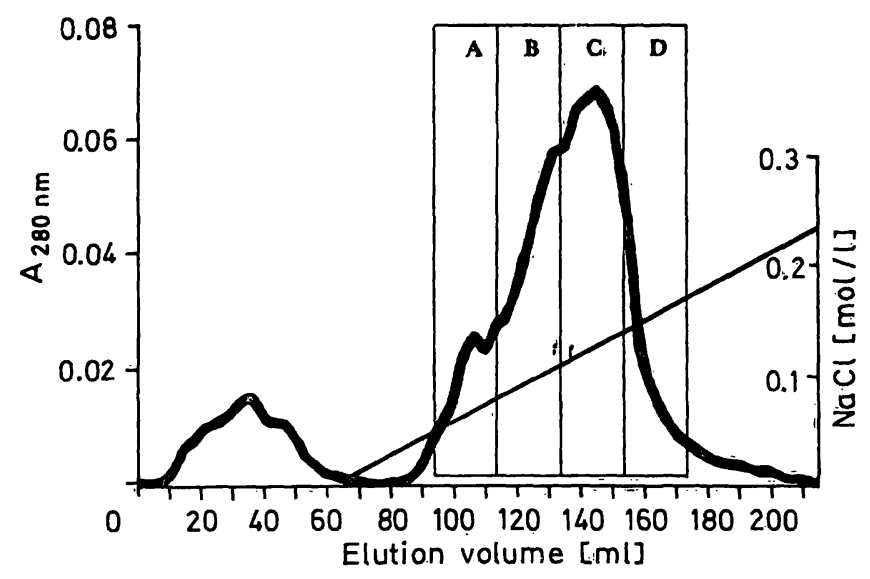

Fig. 1. Elution of glomerular NC1 from CM 52-cellulose by a $\mathrm{NaCl}$ gradient.

The clarified digest was subjected to ion exchange chromatography on diethylaminoethyl-cellulose (DE-52, Whatman, UK) in $8 \mathrm{~mol} / \mathrm{l}$ urea buffered to $\mathrm{pH}$ 7.5. The eluted proteins were applied to a carboxymethyl-cellulose column (CM-52, Whatman) in $8 \mathrm{~mol} / \mathrm{l}$ urea buffered to $\mathrm{pH}$ 4.8. Glomerular NC1 (known to contain Goodpasture antigens) was eluted in a broad inhomogeneous peak by a gradient of $0-0.3 \mathrm{~mol} / \mathrm{l} \mathrm{NaCl}$ (fig. 1). Fractions $A-D$ were diluted with a 10 -fold volume of 10 $\mathrm{mmol} / \mathrm{l}$ sodium acetate in ethanol. Fraction A apparently contained impurities and did not form a precipitate. Precipitates from fractions $B-D$ were analysed by sodium dodecylsulphate electrophoresis. To test for their competitive capacity in the NC1 radioimmunoassay, precipitates were also dissolved in radioimmunoassay buffer. The relative protein content of the fractions was estimated by planimetry of the area below the absorbance curve. Type IV collagen was prepared from human placenta by pepsin digestion (16). Various concentrations of the collagen were dissolved in radioimmunoassay buffer to test for competitive capacity in the NC1-radioimmunoassay.

\section{Serum samples}

Radioimmunoassay of immunoreactive NC1 was performed with serum samples collected from 150 women with an uncomplicated course of pregnancy and from 9 patients with preeclamptic symptoms (gestosis index $>4$; all of these patients were hypertensive, oedema was diagnosed in 7 patients and proteinuria in 4 patients). Within each assay we analysed 20 replicates of a serum pool of 30 healthy, nonpregnant women. In the actual assay, NC1 concentrations of pregnancy sera were related to the mean concentration of the pool (defined as one arbitrary unit/ml).

\section{Results}

\section{NC1 radioimmunoassay}

Maximal binding of radiolabeled NC1 to diluted rabbit anti-NC1 serum was about $40 \%$ of total radioactivity. Half maximal inhibition was observed at a NC1 concentration of approximately $25 \mu \mathrm{g} / 1$. The non-specific binding was $3 \%$.

The suitability of the NC1 radioimmunoassay for human serum samples was tested. Serum did not influence the non-specific binding and competed in a dose-dependent manner with the binding of radiola- 


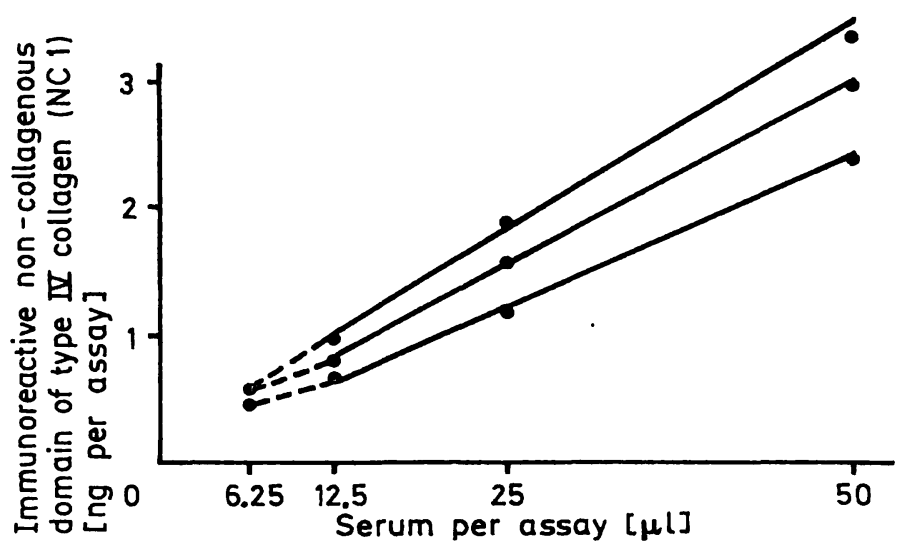

Fig. 2. Linearity of dilution of human sera in the NC1 radioimmunoassay ( 3 samples of non-pregnant women). Half-maximal inhibition of binding was achieved with $2.5 \mathrm{ng}$ placental NC1 per assay.

beled NC1. Linearity of dilution of serum samples was satisfactory at least between 3 and $1 \mathrm{ng} \mathrm{NC1}$ per incubation (fig. 2). Usually, a four-fold dilution was sufficient for the analysis of serum samples at the maximal slope of the calibration curve.

The serum matrix did not influence the recovery of placental NC1: a serum sample, showing competition equivalent to $48.4 \pm 1.6 \mu \mathrm{g} / 1 \mathrm{NC} 1$ (6 replicates, intraassay coefficient of variation: $3 \%$ ), was four-fold diluted and various concentrations of placental $\mathrm{NC1}$ were added. The recovery of added NC1 was calculated after subtraction of the serum contribution (tab. 1).

Tab. 1. Recovery of placental NC1 within a serum matrix.

\begin{tabular}{ll}
\hline NC1 $\mu \mathrm{g} / \mathrm{l}$ added to serum & Recovery (\%) \\
\hline 31.5 & 100 \\
15.8 & 113 \\
7.9 & 97 \\
3.9 & 100 \\
2 & 105 \\
\hline
\end{tabular}

The variation between 15 assays was $17 \%$. However, the inter-assay variation was reduced to $12 \%$ by normalisation of the results to the average concentration of replicates from a serum pool, which were measured within the same assay.

\section{Properties of the rabbit anti-NC1 serum IV/8 K2 BE}

Binding behaviour of anti-NC1 serum to reduced placental NC1 was tested by electrophoresis and Western blot analysis. Although monomers increased in partly reduced NC1 (fig 3, compare lane 1 and 6), we observed in Western blots only a weak binding of

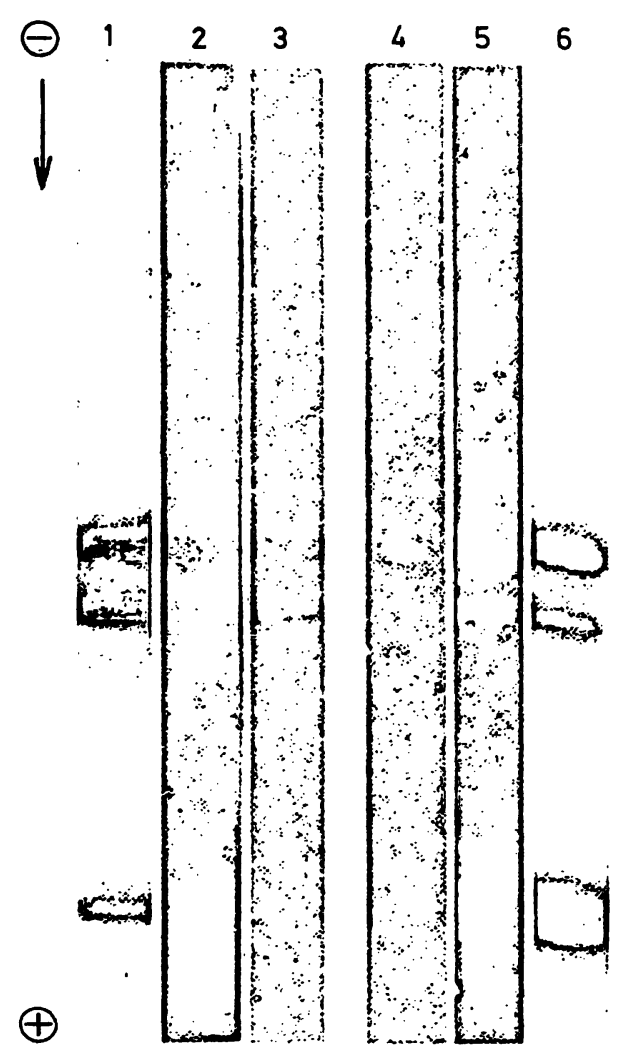

Fig. 3. Sodium dodecylsulphate electrophoresis and Western blots of placental NC1.

Electrophoresis: lane 1 (NC1) and lane 6 (reduced NC1) Western blot analysis: lane 2 and $3(20 \mu \mathrm{g}$ and $2.5 \mu \mathrm{g}$ $\mathrm{NC1}$, respectively), lane 4 and $5(5 \mu \mathrm{g}$ and $20 \mu \mathrm{g}$ reduced $\mathrm{NC1}$, respectively).

anti-NC1 to reduced monomers. In addition, binding to reduced dimers was also diminished (lanes 2, 3 and 4,5 ; note that line 4 contained twice as much protein as line 3 ).

The competitive capacity of NC1 subunits obtained by dissociation of the globulin with urea was tested in the NC1 radioimmunoassay. Fractions from collagenase-digested glomerular basement membranes (19) were used, since monomers and dimers were partly separated by carboxymethyl-cellulose chromatography (fig. 1) as shown by electrophoresis of fractions B-C (fig. 4). Fraction B contained predominately monomer forms and fractions $\mathrm{C}$ and $\mathrm{D}$ were rich in dimers. Considering the protein content, these latter fractions had a higher competitive capacity in the NC1 radioimmunoassay than the monomer fraction B (tab. 2).

Tab. 2. Relative protein content $\left(\mathrm{A}_{280 \mathrm{~nm}}\right)$ and relative immunoreactive NC1 content of fractions from $\mathrm{CM} 52$-cellulose chromatography (fig. 1).

$\begin{array}{ll}\text { Fraction } & \text { B C D } \\ \text { Protein } & 4: 5: 1 \\ \text { Immunoreactive NC1 } & 1: 10: 1\end{array}$




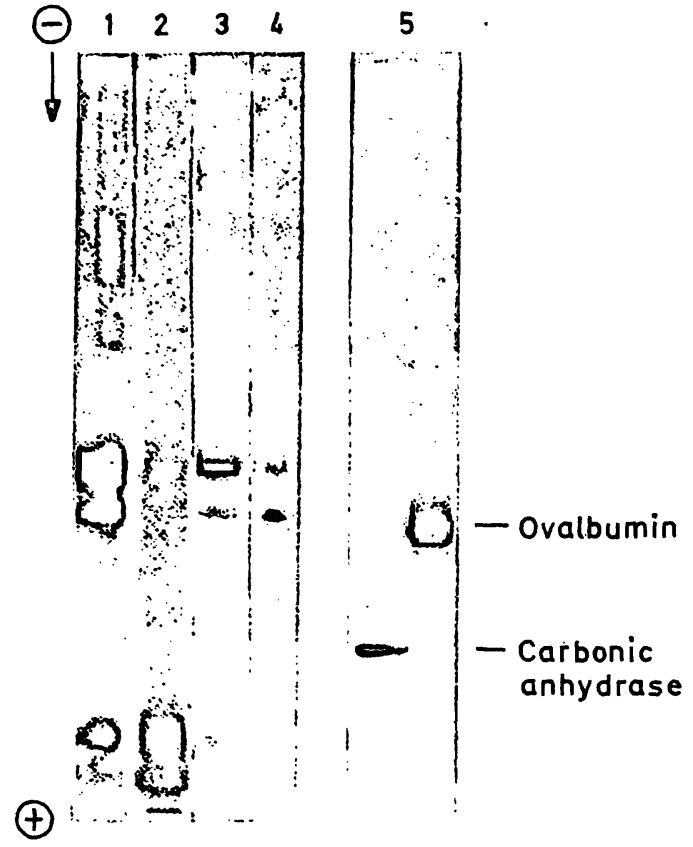

Fig. 4. Sodium dodecylsulphate electrophoresis of fractions obtained by CM-cellulose chromatography (see fig. 1).

Lane 1: protein mixture before chromatography. Lane 2: fraction $B$, lane 3: fraction $C$, lane 4: fraction $D$. Lane 5: Ovalbumin and carbonic anhydrase were used as protein standards.

Serum NC1 may be linked to type IV collagen fragments $(13,14)$. To test wether the anti-NC1 serum cross-reacts with other determinants of the collagen, we used a pepsin-extracted type IV collagen preparation (16) lacking NC1 for displacement experiments. Event at a 500 -fold molar excess of collagen, no inhibition was detectable.

\section{Concentrations of immunoreactive $\mathrm{NC1}$ in pregnancy}

During the second trimester of pregnancy the serum concentrations of immunoreactive NC1 increased to values about 1.4-fold above those of non-pregnant women (fig. 5). Levels dropped with onset of the third trimester, but an additional increase was noticed toward end of pregnancy. The mean serum concentration of patients with preeclamptic symptoms was slightly elevated.

\section{Discussion}

Information on basement membrane turnover in animals and men may be derived from radioimmunologic measurements of fragments from its macromolecular components $(2,13,14,20,21)$. Cross-linked regions of type IV collagen like NC1 or 7S (3) seem to be suitable for this purpose, since they are involved in the formation of collagen structures, and their antigenicity facilitates preparation of specific antisera.

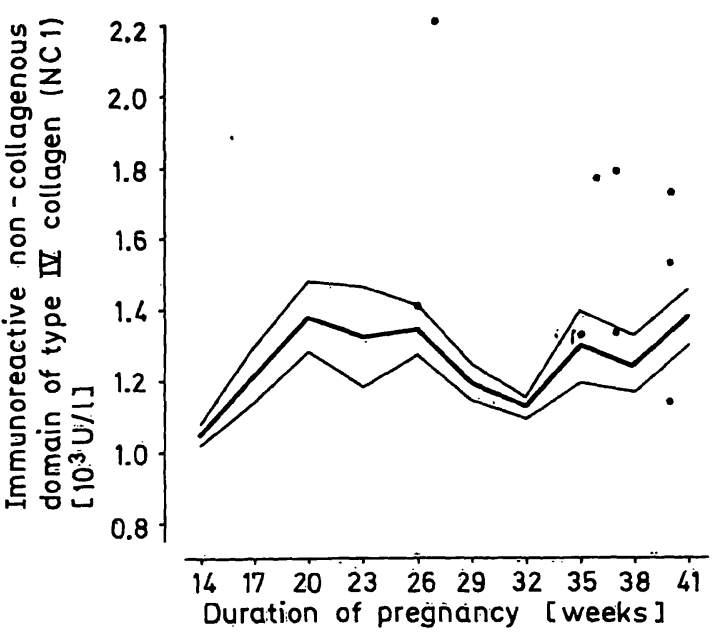

Fig. 5. Serum concentrations of immunoreactive serum NC1 during pregnancy. Mean \pm standard error mean were calculated from three weekly intervals (about 15 women per interval) and from patients with preeclamptic symptoms ( $(\bullet)$.

The use of a magnetic separation agent in the NC1 radioimmunoassay improved the assay procedure, since immunoprecipitates often form fluffy pellets (own observations). The assay was suitable for concentration measurements in human sera as shown by dilution and recovery experiments (fig. 2, tab. 1), although inhibition curves showed some nonparallelity especially at high and low concentrations of serum inhibitor (not shown).

The concentration of placental NC1 necessary for a half maximal inhibition was higher in our assay compared with former methods; but we obtained half maximal inhibition with about $40 \mu$ of normal human serum (fig. 2), whereas other investigators reported about $100 \mu \mathrm{l}(1,2)$.

The properties of the anti-NC1 serum IV/8 K2BE were similar to those reported for other NC1-antisera $(1,2,7)$, with respect to diminished reactivity with reduced NC1 (fig. 3), monomers (tab. 2) and lack of cross-reaction with other domains of type IV collagen. Some properties of these antisera may complicate interpretation of radioimmunoassay results. The high molecular weight of immunoreactive serum NC1 in rats indicated a link to collagen chains $(13,14)$, but in men suffering from fibrotic liver disease, the fragments detected were mainly similar in size to NC1 subunits (2). Escape of type IV collagen molecules during the synthesis of the network, as well as degradation, may explain these findings (14). Since the molecular forms of the antigen (intact globular structure, subunits, linked to collagen fragments) are widely unknown in different human serum samples, and the affinity of the antiserum apparently depended on the integrity of disulphide bridges and on the monomer/dimer ratio, all these factors may influence 
radioimmunoassay results. It cannot be excluded that apparent serum concentrations mainy reflect a bulk of NC1 dimers and oligomers partly linked to type IV collagen fragments and that enhanced dissociation and degradation to monomers (which are not so well detected) cause an underestimation of concentrations.

Thus, in our study on serum samples only immunoreactive $\mathrm{NC1}$ was measured and we decided to express concentrations relative to a pool of healthy, nonpregnant women.

The complicated course of immunoreactive serum NC1 during pregnancy may be related to placental development (fig. 5). Although the placenta has attained its definitive form and thickness during the first trimester of pregnancy, growth in circumference continues to the end of pregnancy. During the second trimester important morphologic changes occur: the placental villi increase in number, their stroma becomes more compact and is now separated from the trophoblast by a distinct basement membrane (22). It is possible that these morphological changes are reflected by the transitory increase of immunoreactive serum NC1 during the second trimester, while the increase of concentration toward the end of pregnancy may result from further placental growth. Recently we observed a similar increase of immunoreactive laminin toward the end of pregnancy, but there was no peak during the second trimester (20).

Preeclampsia represents a rare but severe risk for the life of pregnant women and is often connected to placental and renal injury. The aetiology is unknown. But as in the case of laminin (20), immunoreactive $\mathrm{NC} 1$ tended to be elevated in patients with preeclamptic symptoms (fig. 5). Concentration changes of these parameters may reflect degradation as well as an enhanced basement membrane synthesis, due to an impaired functional integrity of the membranes. The latter may be concordant with the characteristic thickening of trophoblast basement membranes detected in preeclamptic placentas (23). Combined observations, together with recent findings on circulating serum antibodies against laminin and type IV collagen in preeclampsia $(24,25)$, further support the hypothesis of an involvement of basement membranes and antibodies in the pathophysiology of this disease.

\section{Acknowledgement}

We thank Dr. H. Strecker $\dagger$ from the Radiochemical Laboratory and Dr. D. Brocks from the Biochemical Department of Hoechst AG, Frankfurt, FRG, for their interest and support of this work. A gift of magnetic separation agent from Serono, Freiburg, FRG is gratefully acknowledged. We thank Dr. Endler and Dr. Rudelstorfer for the collection of blood.

\section{References}

1. Mark, H., Oberbäumer, I., Timpl, R., Kemler, R. \& Wick, G. (1985) Eur. J. Biochem. 146, 555- 562.

2. Schuppan, D., Besser, M., Schwarting, R. \& Hahn, E. (1986) J. Clin. Invest. 78, 241-248.

3. Timpl, R., Oberbäumer, I., Furthmayr, H. \& Kuehn, K. (1982) In: New Trends in Basement Membrane Research (Kühn, K., Schöne, H. \& Timpl, R., eds.) pp. 57-67, Raven Press, New York.

4. Weber, S., Engel, J., Wiedemann, H., Glanville, R. \& Timpl, R. (1984) Eur. J. Biochem. 13.9, $401-410$.

5. Kuehn, K., Glanville, R., Babel, W., Qian, R.-Q., Dieringer, H., Voss, T., Siebold, B., Oberbäumer, I., Schwarz, U. \& Yamada, Y. (1985) In: Ann. New York Acad. Sci. (Fleischmajer, R., Olsen, B. \& Kühn, K., eds.) Vol. 560, pp. 14-24.

6. Oberbäumer, I., Laurent, M., Schwarz, U., Sakurai, Y., Yamada, Y., Vogeli, G., Voss, T., Siebold, B., Glanville, R. \& Kühn, K. (1985) Eur. J. Biochem. 147, $21 \overline{7}-224$.

7. Timpl, R., Oberbäumer, I., Mark, H., Bode, W., Wick, G., Weber, S. \& Engel, J. (1985) In: Ann. New York Acad. Sci. (Fleischmajer, R., Olsen, B. \& Kühn, K., eds.) Vol. 460, pp. $58-72$.

8. Wieslander, J., Bygren, P. \& Heinegard, D. (1984) Proc. Natl. Acad. Sci. USA 81, 1544-1548.

9. Wieslander, J., Barr, J., Butkowski, R., Edwards, S., Bygren, P., Heinegard, D. \& Hudson, B. (1984) Proc. Natl. Acad. Sci. USA 81, 3838-3842.

10. Kleppel, M., Michael, A. \& Fish, A. (1986) J. Biol. Chem. 261, 16547-16552.

11. Butkowsky, R., Wieslander, J., Wiesdom, B., Barr, J., Noelken, M. \& Hudson, B. (1985) J. Biol. Chem. 260, $3739-3747$.

12. Butkowsky, R., Langeveld, J., Wieslander, J., Hamilton, J. \& Hudson, B. (1987) J. Biol. Chem. 262, 7874-7877.
13. Brocks, D., Neubauer, H. \& Strecker, H. (1985) Diabetologia 28, 928-932.

14. Savolainen, E., Brocks, D., Ala-Kokko, L. \& Kivirikko, K. (1988) Biochem. J. 249, 753-757.

15. Bolton, E. \& Hunter, W. (1973) Biochem. J. 133, 529-539.

16. Glanville, R., Rauter, A. \& Fietzek, P. (1979) Eur. J. Biochem. 95, 383-389.

17. Miller, E. \& Rhodes, R. (1982) In: Methods in Enzymology (Cunningham, L. \& Fredrikson, D., eds.) Vol. 82, pp. 3364, Academic Press, New York.

18. Wray, W., Boulikas, T., Wray, V. \& Hancock, R. (1981) Anal. Biochem. 118, 197-203.

19. Wieslander, J. \& Heinegard, D. (1985) In: Ann. New York Acad. Sci. (Fleischmajer, R., Olsen, B. \& Kühn, K., eds.) Vol. 460 , pp. $363-374$.

20. Bieglmayer, C., Feiks, A. \& Rudelstorfer, R. (1986) Gyn. Obstet. Invest. 22, 7-11.

21. Niemelä, O., Risteli, L., Sotaniemi, E. \& Risteli, J. (1985) Eur. J. Clin. Invest. 15, 132-137.

22. Fox, H. (1978) In: Major Problems in Pathology (Bennington, J., ed.) Vol. 7, pp. 1-37.

23. Fox, H. (1978) In: Major Problems in Pathology (Bennington, J., ed.) Vol. 7, pp. 149-197.

24. Foidart, J., Hunt, J., Lapiere, M., Nusgens, B., De Rycker, C., Bruwier, M., Lambotte, R., Bernard, A. \& Mahieu, P. (1986) Kidney Int. 29, 1050-1057.

25. Bieglmayer, C., Rudelstorfer, R., Bartl, W. \& Janisch, H. (1986) Brit. J. Obstet. Gynecol. 93, 815-822.

Dr. Ch. Bieglmayer

2nd Department of Obstetrics and Gynecology

University Hospital of Vienna

Spitalgasse 23

A-1090 Vienna 
$-2$ 